\title{
An original approach to the diagnosis of scoline- induced apnoea
}

\author{
A. FISHTAL, R. T. EVANS, AND C. N. CHAPMAN \\ From the Department of Pathology, Southmead General Hospital, Bristol
}

SYNOPSIS A new technique is described for measuring the rate of scoline hydrolysis by plasma cholinesterase, which may prove useful in the diagnosis of scoline sensitivity. The importance of extensive family screening is emphasized and three cases possessing a silent gene are described.

Postoperative apnoea is a common problem in anaesthetic practice. Many causes are known, including overdose of the premedication or induction agent, acidosis, and hyperventilation (Benatar, 1970). A proportion of patients can be shown to be abnormally sensitive to the muscle relaxant scoline (suxamethonium, succinyl dicholine). It is believed that the predisposition to scoline apnoea is genetically determined and due to a structural defect in plasma cholinesterase (pseudocholinesterase, acetyl choline acyl hydrolase E.C. 3.1.1.8.), the enzyme thought to be responsible for scoline breakdown. This defect results in delayed destruction, and hence prolonged action, of the drug.

In 1957 Kalow and his colleagues described dibucaine, a selective inhibitor of plasma cholinesterase. This finding enables patients to be divided into three groups, namely, normal, heterozygous, and homozygous abnormal on the basis of the percentage inhibition of their enzyme by $10^{-5} \mathrm{M}$ dibucaine (Kalow and Genest, 1957; Kalow and Staron, 1957).

The finding of a normal dibucaine number in patients suspected of having had scoline apnoea led to a search for further inhibitors in order to discover genetic variants of the enzyme which would account for the decrease in its activity. Fluoride, butanol, and sodium chloride are now being used for this purpose (Whittaker, 1970). Silent genes have also been demonstrated which, in the heterozygote, lead toa low enzyme level with a normal dibucaine number, and in the homozygote to a complete absence of the enzyme (Liddell, Lehmann, and Silk, 1962).

While these investigations are of considerable biochemical and genetic interest, the use of such parameters for the diagnosis of scoline sensitivity is an indirect approach. This communication describes a method which, we believe, will help to solve Received for publication 25 January 1972. this problem by a direct identification of scolinesensitive individuals.

\section{Materials and Methods}

\section{SPECIMENS}

Blood was collected from a number of patients at this hospital who presented with postoperative apnoea. Where appropriate samples were also collected from their families.

Serum cholinesterase levels and dibucaine numbers were estimated on all specimens, and patients labelled as normal, heterozygous, or homozygous on the basis of their dibucaine numbers. Measurements were performed in duplicate and by the same analyst.

Scoline hydrolysis rates were measured on serum from 31 normals, 17 heterozygotes, and 10 homozygotes.

\section{CHOLINESTERASE}

This was measured in the Astrup apparatus by the method of Johnson and Whitehead (1965).

\section{DIBUCAINE NUMBERS}

Using the Unicam SP800 spectrophotometer the dibucaine numbers were determined according to the method described by Varley (1967).

\section{SCOLINE HYDROLYSIS RATES}

The hydrolysis of succinyl dicholine yields succinyl monocholine and, more slowly, succinic acid. The $p \mathrm{H}$ change due to release of these substances has been measured using a modification of the cholinesterase method.

Since there are two products of the reaction, released in unknown relative proportions, it is impossible to report enzyme activity in terms of 
International Units/litre. It has therefore been reported in $\mathrm{pH}$ units.

The substrate is $10 \mathrm{mM}$ succinyl dicholine: 0.3937 $\mathrm{g} / 100 \mathrm{ml}$ succinyl choline chloride (Sigma Ltd). Stored at $4^{\circ} \mathrm{C}$ this is stable for at least four weeks.

Serum, 0.05 ml, was equilibrated for three minutes with $4 \% \mathrm{CO}_{2}$ in oxygen at $37^{\circ} \mathrm{C}$ in the tonometer of the Astrup micro apparatus. Then $0.05 \mathrm{ml}$ of substrate was added and shaking continued for a further 15 seconds. An aliquot of the enzyme substrate mixture was sucked into the micro electrode and the $p \mathrm{H}$ of this solution measured. The $p \mathrm{H}$ readings were noted at timed intervals over the next 25 minutes. In order to make the best use of all the readings, regression coefficients and coefficients of linear correlation were calculated using an Olivetti Programma 101. The reported $p \mathrm{H}$ change was then 25 times the rate of regression.

\section{Results}

The three families examined in detail are shown in Figures 1, 2, and 3. Ninety-one patients were investigated during the course of this work of whom 10 were abnormal, 29 were heterozygous, and 52 normal. Mean results for cholinesterase and dibucaine numbers for the three groups are shown in Table I. These results compare well with those previously reported (Johnson and Whitehead, 1965; Harris and Whittaker, 1961).

Scoline hydrolysis rates are compared with serum cholinesterase in Fig. 4, and with dibucaine numbers in Figure 5.

The mean scoline hydrolysis rates of the homo-

\begin{tabular}{|c|c|c|c|c|c|}
\hline \multirow[t]{2}{*}{ Patient } & \multirow{2}{*}{$\begin{array}{l}\text { No. } \\
\text { of } \\
\text { Cases }\end{array}$} & \multicolumn{2}{|c|}{ Cholinesterase } & \multicolumn{2}{|c|}{ Dibucaine No. } \\
\hline & & Mean & $S D$ & Mean & $S D$ \\
\hline $\begin{array}{l}\text { Normal } \\
\text { Heterozygous } \\
\text { Homozygous } \\
\text { abnormal }\end{array}$ & $\begin{array}{l}52 \\
29 \\
10\end{array}$ & $\begin{array}{r}385 \\
258 \\
83\end{array}$ & $\begin{array}{l}68 \\
72 \\
17\end{array}$ & $\begin{array}{l}81 \\
61 \\
20\end{array}$ & $\begin{array}{l}3 \cdot 5 \\
5 \\
5 \cdot 3\end{array}$ \\
\hline
\end{tabular}

Table I Mean and standard deviations for serum cholinesterase and dibucaine number on 52 normal, 29 heterozygous, and 10 homozygous abnormal patients

zygous abnormals was $\mathbf{0 . 0 3 0}$ with a maximum value of 0.044 . Of the 17 hererozygotes, 16 fell within the range 0.073-0.141. The seventeenth case (M.P.R.) was, however, exceptional, having a value of 0.195. Excluding this case, there is a clear difference

\begin{tabular}{|c|c|c|c|}
\hline \multirow[t]{2}{*}{ Patient } & \multirow{2}{*}{$\begin{array}{l}\text { No. } \\
\text { of } \\
\text { Patients }\end{array}$} & \multicolumn{2}{|c|}{ Scoline Hydrolysis Rates } \\
\hline & & Mean & Range \\
\hline $\begin{array}{l}\text { Normal } \\
\text { Heterozygous } \\
\text { Homozygous abnormal }\end{array}$ & $\begin{array}{l}31 \\
16 \\
10\end{array}$ & $\begin{array}{l}0 \cdot 186 \\
0 \cdot 106 \\
0.030\end{array}$ & $\begin{array}{l}0 \cdot 149-0 \cdot 261 \\
0 \cdot 073-0 \cdot 141 \\
0 \cdot 010-0 \cdot 044\end{array}$ \\
\hline
\end{tabular}

Table II Scoline hydrolysis rates in 31 normal, 16 heterozygous, and 10 homozygous abnormal patients

between the heterozygous and normal ranges, the range for normal being $0 \cdot 149-0 \cdot 261$. The results, with the exception of those for M.P.R., are summarized in Table II.

To ascertain whether calculation of a regression coefficient was a necessary step in the measurement of scoline hydrolysis rates, the mean difference
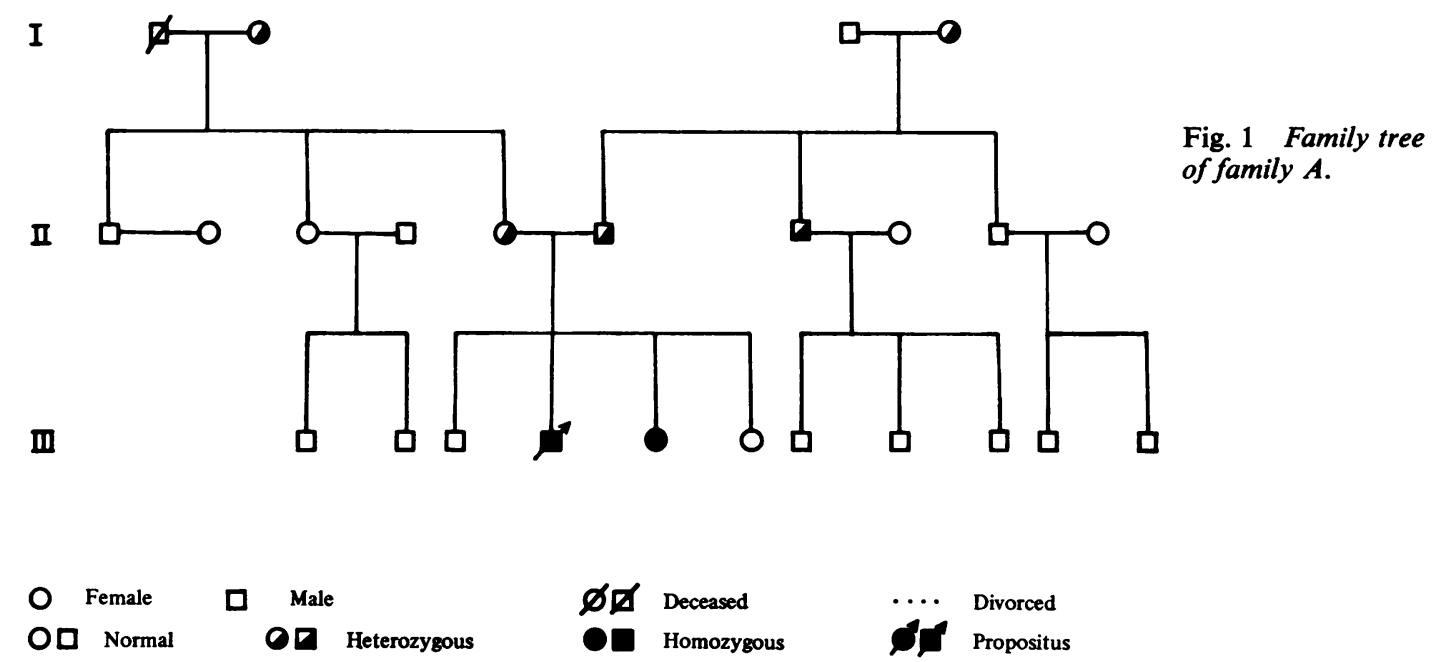
A. Fishtal, R. T. Evans, and C. N. Chapman $\stackrel{\complement}{\bar{\Xi}}$

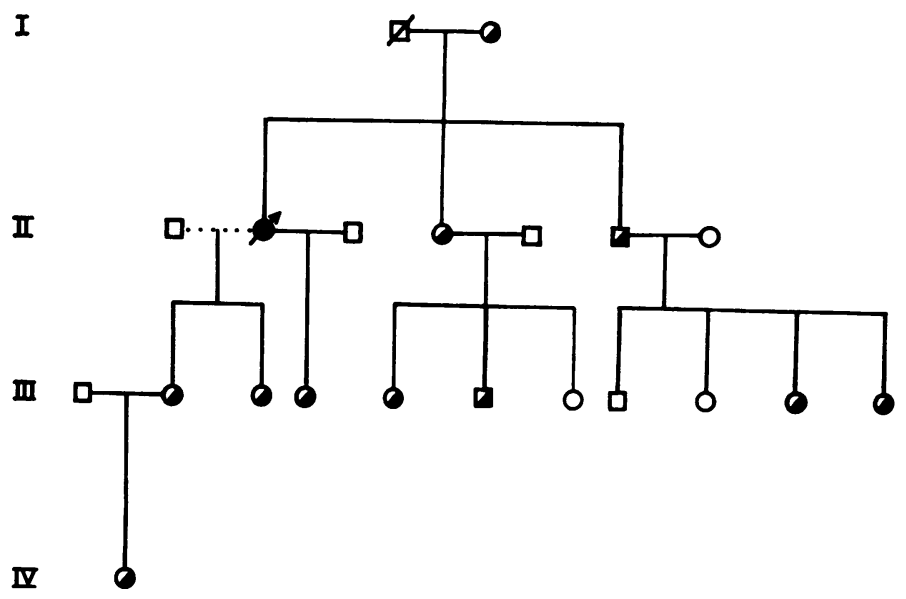

Fig. 2 Family tree of family $B$.

Fig. 3 Family tree of family $C$.

Fig. 4 The relationship between scoline hydrolysis rates and serum cholinesterase.

Fig. 2.

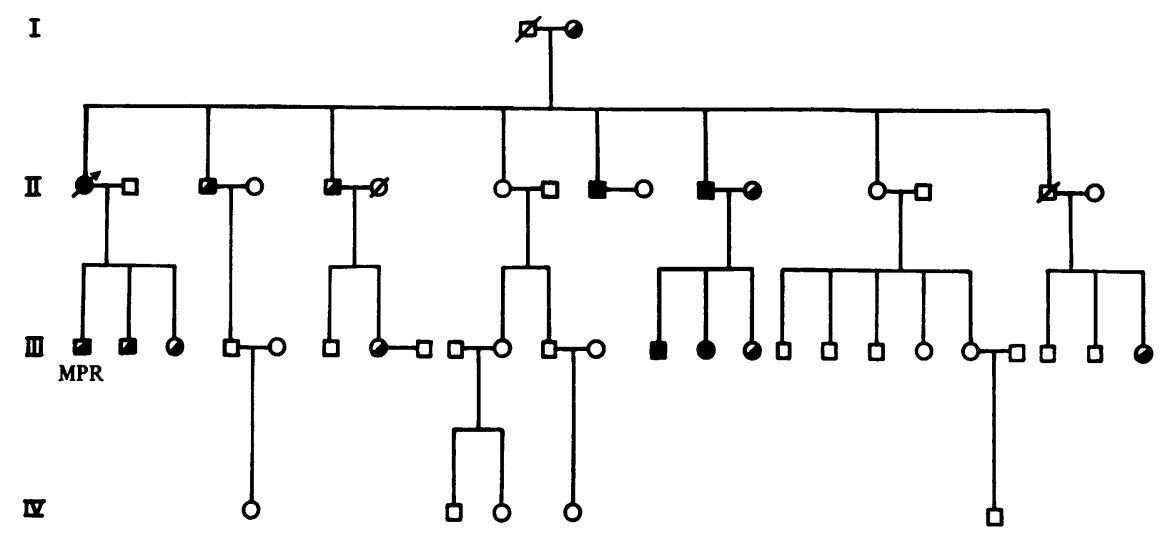

Fig. 3.

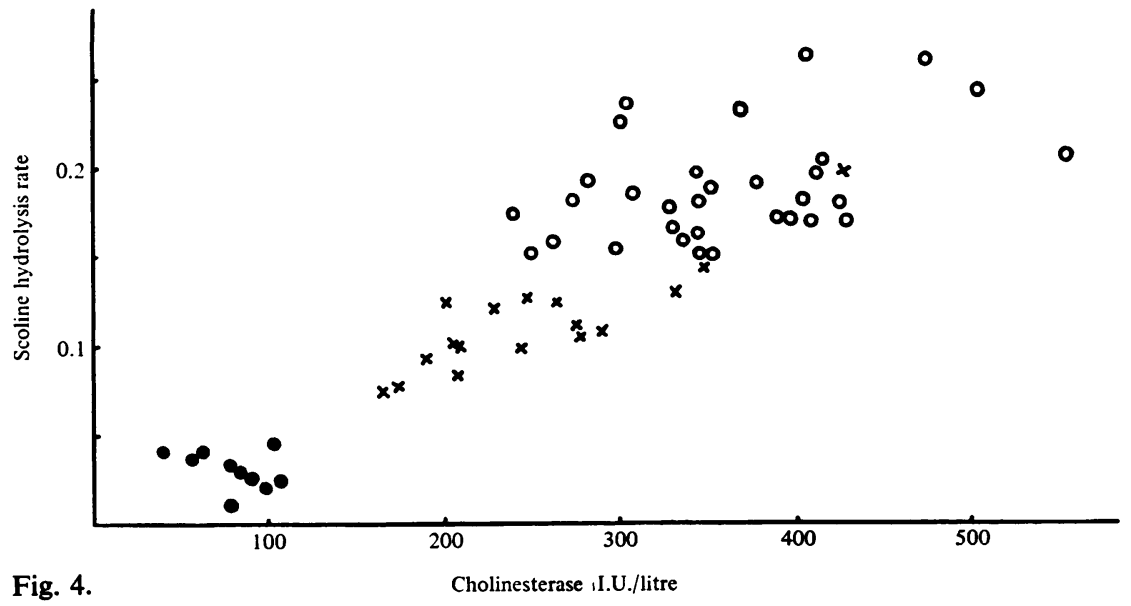

Fig. 4.

Cholinesterase II.U./litre 


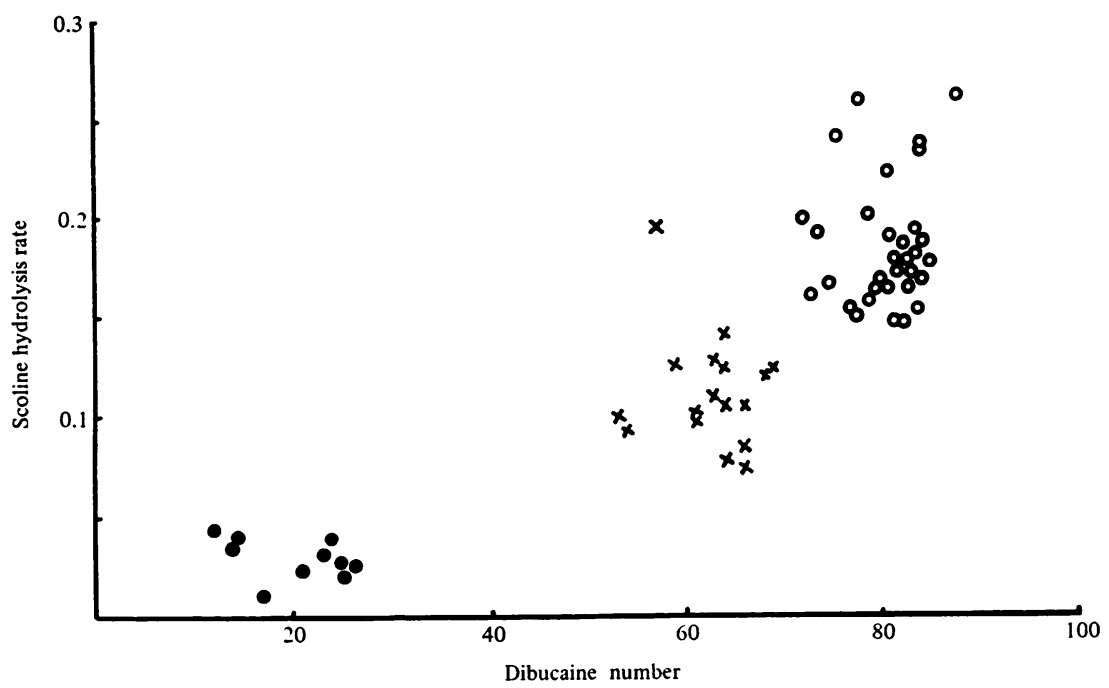

Fig. 5 The relationship between scoline hydrolysis rates and dibucaine number. between the measured and calculated $p H$ changes over the 25-minute incubations was determined. This was $0.004 \mathrm{pH}$ units, with a maximal difference of $0.012 \mathrm{pH}$ units. Although these differences are small, it seemed wise to calculate the regression coefficient since the necessary computing facilities were available.

For the 58 scoline hydrolysis rates estimated the mean coefficient of linear correlation of the fall in $p \mathrm{H}$ against time was $\mathbf{0 . 9 8 0}$, indicating a high degree of linearity. Spontaneous $p \mathrm{H}$ change over the 25minute incubation, when substrate was replaced by water, lay in the range -0.01 to $+0.01 p \mathrm{H}$ units. This was sufficiently small not to contribute significantly to experimental errors. These changes were probably due to instrumental fluctuation rather than a true alteration in the $p H$ of the solution, since buffers exhibited a similar variation in reading when incubated over this period of time.

The error of the method varied between the three groups. Replicate analyses resulted in the following

\begin{tabular}{llll}
\hline & $\begin{array}{l}\text { Dibucaine } \\
\text { No. }\end{array}$ & $\begin{array}{l}\text { Cholinesterase } \\
(1 \text { u/l) }\end{array}$ & $\begin{array}{l}\text { Scoline } \\
\text { Hydrolysis } \\
\text { Rate }\end{array}$ \\
\hline 1 P.G.W. & 64 & 259 & $0 \cdot 120$ \\
2 B.A.W. & 86 & 208 & 0.080 \\
3 B.W. & 16 & 54 & 0.043 \\
4 S.W. & 33 & 56 & 0.014 \\
5 P.W. & 83 & 303 & $0 \cdot 174$ \\
\hline
\end{tabular}

Table III Serum cholinesterase, dibucaine numbers, and scoline hydrolysis rates for the members of family $D$

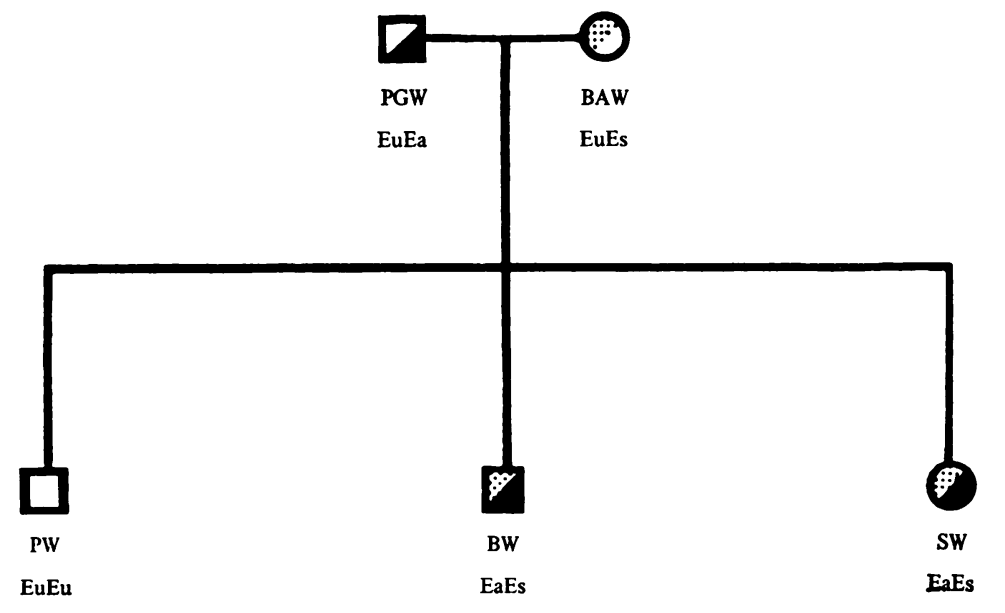

Fig. 6 Family tree of family $D$ including proposed genotypes. Eu Normal allele; Ea abnormal allele; Es silent allele. 
coefficients of variation being obtained, $9 \%$ for the abnormal group, $5 \%$ for the intermediate group, and $4 \%$ for the normal subjects.

A family not described above has also been investigated (Fig. 6 and Table III).

\section{Discussion}

It is apparent from Figs. 4 and 5 that the separation of normal, heterozygous, and abnormal subjects by the determination of scoline hydrolysis rates is superior to that achieved by the cholinesterase method alone. Overlap is seen in only one case, M.P.R., a heterozygote, with a serum cholinesterase level of $419 \mathrm{IU} /$ litre (1 standard deviation above the mean for normal subjects). In view of this otherwise good separation, it is possible that a test of this type may eventually replace existing cholinesterase methods for the investigation of these patients.

Whittaker and Vickers (1970) reported 53 patients presenting with postoperative apnoea. Twenty-one were found to have a normal phenotype and, of these, 10 also had normal levels of enzyme activity. Similar groups of patients have been described by other workers (Kalow, 1965; Lehmann and Liddell, 1969) in whom, despite a normal phenotype, scoline sensitivity could not be excluded as a cause of the apnoea. We have had two cases in this category shown in Table IV. In both, scoline hydrolysis rates were well within the range for normal subjects. This enabled us to conclude that scoline sensitivity was unlikely to be the cause of their apnoea.

\begin{tabular}{llll}
\hline Patient & $\begin{array}{l}\text { Dibucaine } \\
\text { No. }\end{array}$ & $\begin{array}{l}\text { Cholinesterase } \\
(1 \text { u/l })\end{array}$ & $\begin{array}{l}\text { Scoline } \\
\text { Hydrolysis } \\
\text { Rate }\end{array}$ \\
\hline E.B. & 84 & 343 & $0 \cdot 235$ \\
R.A. & 85 & 429 & 0.239 \\
\hline
\end{tabular}

Table IV Cholinesterase, dibucaine numbers, and scoline hydrolysis rates on patients E.B. and R.A.

The results on family $D$ are anomalous as their dibucaine numbers cannot be explained solely on the basis of normal and abnormal genes. This anomaly can be resolved by postulating that B.A.W. has one normal and one silent gene (Fig. 6). This patient is interesting since she was the only subject investigated and found to have a normal dibucaine number but a scoline hydrolysis rate within the heterozygous range. In view of this scoline hydrolysis rates may prove useful in the identification of silent genes.

The incidence of the homozygous phenotype in the general population is $1: 2800$ and of the heterozygous phenotype 1:25 (Karlow and Gunn, 1958).

These statistics must be borne in mind when investigating an affected family, and emphasize the need for full family screening, although this is often a laborious and time-consuming procedure. The value of screening is shown in family $\mathbf{C}$ where two brothers of the affected patient were found to be homozygous abnormal. Furthermore one of the brothers was married to a heterozygote, this resulting in two of their three children being homozygous abnormal.

Of the 10 homozygous abnormal subjects reported in this paper, five are known to have had postoperative apnoea. Since all 10 have scoline hydrolysis rates within the same range, it is reasonable to assume that the other five would be sensitive to scoline also. However, further work is required to establish the scoline hydrolysis rate above which a patient is free from risk.

Dibucaine is the only enzyme inhibitor which has been used in this work despite the large number of alternatives available. Dibucaine was selected rather than any of the others, since it is probably the only inhibitor in universal use and is the one against which all others are compared, but the use of alternative inhibitors might be valuable in any patients showing a normal phenotype as revealed by the dibucaine number, accompanied by an abnormal ? scoline hydrolysis rate.

We should like to acknowledge with gratitude the help of Dr F. J. Lewis and J. B. Holton in the preparation of this paper and the financial assistance of the Ethel Showering Research Fund. We are also indebted to Mrs D. M. Evans, who typed the manuscript and to many of our colleagues whose advice and criticism have been invaluable.

\section{References}

Benatar, S. R. (1970). Succinylcholine-Prolonged apnoea and some dangers. $S$. Afr. med. J., 44, 999-1002.

Harris, H., and Whittaker, M. (1961). Differential inhibition of human serum cholinesterase with fluoride: recognition of two new phenotypes. Nature (Lond.), 191, 496-498.

Johnson, J. K., and Whitehead, T. P. (1965). Rapid estimation of serum cholinesterase activity using the Astrup micro equipment. J. clin. Path., 18, 435-440.

Kalow, W. (1965). Contribution of hereditary factors to the response to drugs. Fed. Proc., 24, 1259-1265.

Kalow, W., and Genest, K. (1957). A method for the detection of atypical forms of human serum cholinesterase, determination of dibucaine numbers. Canad. J. Biochem., 35, 339-346.

Kalow, W., and Gunn, D. R. (1959). Some statistical data on atypical cholinesterase of human serum. Ann. hum. Genet., 23, 239-250.

Kalow, W., and Staron, N. (1957). On distribution and inheritance of $\sigma$ atypical forms of human serum cholinesterase as indicated by dibucaine numbers. Canad. J. Biochem., 35, 1305-1320.

Lehmann, H., and Liddell, J. (1969). Human cholinesterase (pseudocholinesterase) genetic variants and their recognition. Brit. J. \& Anaesth., 41, 235-244.

Liddell, J., Lehmann, H., and Silk, E. (1962). A 'silent' pseudocholinesterase gene. Nature (Lond.), 193, 561-562.

Varley, H. (1967). Practical Clinical Biochemistry, 4th ed., p. 303. Heinemann, London.

Whittaker, M. (1970). Genetic aspects of succinyl choline sensitivity. Anesthesiology, 32, 143-150.

Whittaker, M., and Vickers, M. D. (1970). Initial experience with the $O$ Cholinesterase Research Unit. Brit. J. Anaesth., 42, 1016-1020. 